\title{
LncRNA-DRSGN (Down-Regulated in Spiral Ganglion Neurons) Competes with miR-27a for Binding to FAM172A, Supervises SGN Degeneration and ER (Endoplasmic Reticulum) Stress-Autophagy in CHARGE Syndrome
}

\section{Xian-Bao Cao}

Kunming University of Science and Technology - Lianhua Campus: Kunming University of Science and Technology

\section{Bi-Zhang Lu}

Kunming University

Jia-Hong Pei

Kunming University of Science and Technology - Lianhua Campus: Kunming University of Science and Technology

\section{Cun Feng}

Kunming University of Science and Technology - Lianhua Campus: Kunming University of Science and Technology

\section{Yan-Fei Guan}

Kunming University of Science and Technology - Lianhua Campus: Kunming University of Science and Technology

\section{Shun-Min Gong}

Kunming University of Science and Technology - Lianhua Campus: Kunming University of Science and Technology

\section{Li Li}

Henan University of Chinese Medicine

\section{Dao-wei Li}

Henan University of Chinese Medicine

\section{Anzhou Tao}

Kunming Medical University

jinqian zhang ( $\nabla$ jingwanghou@163.com)

Kunming Institute of Technology: Kunming University of Science and Technology

https://orcid.org/0000-0003-0765-1183 
Keywords: Long nocoding RNA (LnCRNA), DRSGN (Down-regulated in spiral ganglion neurons), FAM172A gene, ER (Endoplasmic reticulum) stress, autophagy, neuron degeneration, CHARGE syndrome

Posted Date: December 22nd, 2021

DOI: https://doi.org/10.21203/rs.3.rs-1174464/v1

License: (c) (1) This work is licensed under a Creative Commons Attribution 4.0 International License. Read Full License 


\section{Abstract}

Background: Hearing loss is one of the most common disabilities in the world and brings a heavy burden to society. The current model is not stable enough, and it has caused serious model interference to clarify the pathogenesis of CHARGE syndrome.

Methods: The knockout mouse model of FAM172A gene was constructed, and sits phenotype was identified. Besides, the next-genesequencing experiments of noncoding RNAs were performed utilizing the primary SGNs of model mice. The biofunctions of FAM172A in the relationships between ER (Endoplasmic reticulum) stress, autophagy, and intracellular calcium flux were investigated. Moreover, the above role associated with the competitive combination among LncRNA-DRSGN, miR-27a, and FAM172A were studied in the progression of SGN degeneration and autophagy in the model of CHARGE syndrome.

Results: FAM172A(-/-) exhibited abnormal hearing, growth retardation, abnormal eye development, and dysgnosia. It was in line with the phenotype of CHARGE syndrome. Moreover, there was degeneration of SGNs in FAM172 $\mathrm{A}^{(-/)}$mice, and the differential expression of noncoding RNAs in primary SGNs were found and identified, including miR-27a and LncRNA-DRSGN. LncRNA-DRSGN regulated miR-27a as a ceRNA, and miR-27a inhibited FAM172A expression, LncRNA-DRSGN competed with miR-27a for binding to FAM172A, which participated in the regulation of ER stress-related calcium flux. LncRNA-DRSGN regulated the autophagy process of neurons by competing with miR-27a for binding to FAM172A.

Conclusion: LncRNA-DRSGN competed with miR-27a for binding to FAM172A, participated in regulating ER stress-related calcium flux, then affected neuron degeneration and autophagy process of SGNs in the model of CHARGE syndrome.

\section{Introduction}

Hearing loss is one of the most common disabilities in the world and brings a heavy burden to society [1]. The degeneration of SGNs (Spiral ganglion neurons) plays a major role in auditory nerve injury and then causes severe sensorineural hearing loss [2]. In the inner ear, sound is collected and conducted by the external and middle ear, then transformed into electrical signals by cochlear hair cells [3], and then these electrical signals are transduced to the auditory cortex by SGNs [4]. Therefore, replenishing of SGNs will be a promising clinical strategy, which can reconstruct the auditory pathway $[5,6]$.

Moreover, CHARGE syndromes has a rare disease with multiple anomalies, including hearing loss. CHARGE syndrome have been estimated to occur with a birth rate of 1:8000 1:12,000, but can't obtain satisfactory therapy [7]. The cellular homeostasis is major maintained by the catabolic pathway of autophagy [8], thereby playing an important role in many pathologies, such as carcinoma, neurodegeneration, aging, etc $[9,10]$. Autophagy has also been shown to play critical roles in the inner ear [11]. Phagophore formation is the first step of autophagy, the membrane edges of the phagophore prolong and then devour cytoplasm portions $[12,13]$. Thereby, the completed structure of the autophagosome generates edges fusion of membrane. Furthermore, the formation of the autolysosome 
combines the autophagosome with a lysosome, then the content of this single membrane vesicle is degraded [14]. However, the recent mechanism of autophagosome biogenesis is not clear.

Whereas, the current studies confirm that the plasma membrane of different cellular compartments may be associated with the precursors of the autophagosome membranes, such as Golgi, endoplasmic reticulum (ER), and mitochondria [15]. Moreover, the autophagic response can be induced by ER stress [16], which caused by the activation of unfolded protein response comes from misfolded protein accumulation in ER.

We firstly found the FAM172A gene in 2005, when it was named as C5orf21 in Pubmed MEDLline. Moreover, the FAM172A gene was cloned from human hepatocytes by our team, then FAM172A protein was induced to express and purify. Furthermore, rabbit monoclone antibody (mAbs) against FAM172A was produced firstly, too. Our previous experimental data demonstrated the biological functions of FAM172A, which played a suppressor role in Hepatocellular Carcinoma (HCC), and was associated with ER stress [17]. Furthermore, we found that FAM172A regulated intracellular calcium flux, and then apoptosis and autophagy [17]. The death of cells could be regulated by two processes, which included autophagy and apoptosis [18].

In recently, LncRNA-DRSGN was found by our team and our results confirmed that it could competitively combine with miR-27a, then restrained the binding of miR-27a to FAM172A [19]. Thereby, the degradation of FAM172A could be induced by miR-27a. Hence, in this work, the role of FAM172A in the relationships among ER stress, autophagy, and intracellular calcium flux was investigated. Meanwhile, the above biological function associated with the competitive combination among LncRNA-DRSGN, miR-27a, and FAM172A were studied in the progression of SGN degeneration related to hearing loss in CHARGE syndrome.

\section{Materials And Methods}

\section{Mice}

At first, in our lab, the conditional gene targeting a mouse to knockdown exon 1 of FAM172A gene was achieved by CRISPR-Cas9 system [20-23]. Consequently, its genotype was identified with PCR assay. The housed mice utilized the common conditions (ventilated cages, $25^{\circ} \mathrm{C}, 12 \mathrm{~h}: 12 \mathrm{~h}$ cycle of light-dark, autoclaved food and water) at Kunming University of Science and Technology (Kunming, Yunnan Province, China). The isoflurane (Escain ${ }^{\circledR}$ ) was used as an anesthetic (at $3 \%$ induction and $2 \%$ maintenance). Finally, cervical dislocation euthanasia was used in our experiments.

This work was approved by the Experimental Animal Ethics Committee of Kunming University of Science and Technology (Kunming, Yunnan Province, China). and the reference number was 2015-0431.

\section{ABR test}


The test was carried out in a sound proof shielded room at a room temperature of $20 \pm 2{ }^{\circ} \mathrm{C}, 10 \%$ chloral hydrate $(330 \mathrm{mg} / \mathrm{kg})$ was injected intraperitoneally before the test. Until the anesthesia took effect, pierced, the reference electrode was inserted at the midpoint of the coronal suture, and the ground electrode was put into the back of the ear being test. The earphone gave sound, the sound source was 1 $\mathrm{cm}$ away from the auricle, the evoked potential was superimposed and processed by a signal processor, then the test was performed. The stimulus was alternating short sounds (clicks), and the repetition rate was 10 times per second. The main parameters selected in the experiment were channel filtering $32 \mathrm{~Hz}-3$ $\mathrm{KHz}$, scanning time was $10 \mathrm{~ms}$, and superposition was 512 times. The sound intensity in this test started at $110 \mathrm{~dB}$ SPL, when it was close to the threshold and then decreased gradually to $5 \mathrm{~dB}$ SPL one time. The electrophysiological response was induced by the needle electrode. After being amplified and processed, it was displayed on the fluorescent screen in the form of a waveform. The threshold was the brainstem auditory evoked potential wave that could be recognized by the naked eye, which was represented by the sound intensity of wave III. The ABR of normal mice consisted of 4-6 waves, of which the amplitude wave was the largest, the last one disappeared was wave $\nabla$, wave $\nabla$ had good repeatability and stability. Therefore, wave $\triangle$ could be used as the main wave for testing the ABR wave of mice [24]. This experiment was mainly to determine the response threshold of wave III as the ABR threshold of experimental animals. Finally, FAM172 $A^{(-/)}$mice at week 14 were conducted ABR test for assessing hearing function at three frequencies-8, 16, and $32 \mathrm{kHz}$.

\section{The Morris Water Maze experiment}

The experimental training phase was carried out continuously for three days, and four times every day. During training, the mice were placed into the pool and faced the pool wall, the water entered into the pool from four points. Moreover, the required time for the mice to find the underwater hidden platform and stand on it was recorded as the incubation period, expressed in seconds (s). After the mice found the platform, let it stand on the platform for $10 \mathrm{~s}$. If the mice failed to find the platform for $60 \mathrm{~s}$ after entering the water, gently drag it from the water onto the platform and stay for $10 \mathrm{~s}$ before proceeding to the next training. Each mouse was put into the pool from the four water entry points for one training session, with an interval of $30 \mathrm{~s}$ between the two training sessions [25].

Furthermore, the navigation experiments were conducted firstly. It was used to measure the learning and memory acquisition ability in the water maze. The experiment observed and recorded the route map, then the time required for the mice to find and climb on the platform, which was recorded as the incubation period. It was used to measure the ability of the mice to retain the memory of the platform's spatial position after learning to find the platform. After the navigation experiment, the platform was removed and put into the water from the same entry point, and the time it took to reach the original platform for the first time and the number of times it traversed the original platform were measured [26].

\section{Cochleae staining}

The bilateral cochleae were obtained from model mice and control mice, respectively. Then all cochleae was sectioned after the progresses of fixation, decalcification, dehydration, and low-temperature 
embedding with cryotome. Consequently, $8 \mu \mathrm{m}$ thickness slices were earned and paralleled to the modiolus axis, then stained with hematoxylin and subsequently eosin after dryness using thermostatic dryer $\left(60^{\circ} \mathrm{C}\right)$.

\section{The count of SGNs (Spiral ganglion cells)}

The count of SGNs (Spiral ganglion cells) was performed based on the previously described method [27]. After Toluidine Blue staining, SGNs were counted in each cochlea.

\section{SGN cells sorted by magnetic beads}

When the positive cells were separated, the specific magnetic beads bound to the target SGNs were utilized and then pulled the magnetic bead/cell complex onto the magnetic shelf. Finally, the supernatant was discarded to obtain your purified target SGN cells.

\section{Cell culture}

The primary SGN cells were obtained from mice based on the above approach. The primary SGNs and mouse neuron cell line Neuro 2A were cultured in DMEM medium contained with FBS.

\section{Next-gene sequencing for noncoding RNAs of SGNs}

Non-coding RNA-sequencing experiments were performed for extraction of SGN RNAs from model mice and control mice. Then, the sequencing data were analyzed for confirming the differential miRNAs and IncRNAs with Ball gown software [28].

\section{qRT-PCR}

The expressions of miR-27a and IncRNA-DRSGN in SGNs were valuated utilizing assays of TaqMan miRNA, SYBR Green dye was used for the quantity of micorRNAs and IncRNAs with qRT-PCR method. The sequences of primers for miR-27a and IncRNA-DRSGN were shown in Table 1.

Table 1

Primers sequences of RNA or DNA oligonucleotides for RT-PCR.

\begin{tabular}{|lll|}
\hline & Sense strand/sense primer (5'-3') & Antisense strand/antisense primer (5'-3') \\
\hline miR-27a & CTAATCGTGTTCACAGTGGCTAAG & TATGGTTTTGACGACTGTGTGAT \\
\hline DRSGN & CAACGAGAAGCCGATGTA & GATGTGTCTAATGGTTCTGAG \\
\hline U6 & TGGAACGCTTCACGAATTTGCG & GGAACGATACAGAGAAGATTAGC \\
\hline
\end{tabular}

\section{The plasmid transfections}

The plasmid transfections were performed with jetPRIME agent (Polyplus-transfection, IllkirchGraffenstaden, France) to achieve stable overexpression of LncRNA-DRSGN. The siRNA of LncRNA- 
DRSGN and mimics of miR-27a was purchased from Qiagen. The overexpression of LncRNA-DRSGN was constructed with pcDNA5/FRT/TO vector.

\section{RNA pull-down}

As the ceRNA was proved that miR-27a was regulated by IncRNA-DRSGN. Moreover, RNA pull-down was conducted to determine the combination between RISC complex and LncRNA-DRSGN. Subsequently, LnCRNA-DRSGN was biotin-labeled after in vitro transcription with biotin RNA labeling mix (Roche). Furthermore, the above products were dealt with RNasE-Free DNase I (Roche), then incubated with the extraction of primary SGNs. After addition of streptavidin agarose beads (Invitrogen), western blot was performed to detect Ago 2 protein, and the expression level of miR-27a was tested with qRT-PCR from pellets of pulled down assay.

\section{Western blot analysis}

The protein electrophoreses were conducted on SDS-PAGE gel. Moreover, the blocked membrane transferred with proteins was dealt with skim milk and probed with primary antibody. The primary antibodies were utilized in our work, including $\beta$-actin (13E5) (Cell Signaling, Danvers, MA, USA; CST 4970S, dilution 1: 2,000), FAM172A (Abcam; ab 121364: dilution 1:2,000), anti-GRP78/BiP antibody (ab21685, 1:800; Abcam, Cambridge, MA, USA); anti-CHOP antibody (L63F7, CST2895, 1:1,000; Cell Signaling, Danvers, MA, USA); anti-LC3 (M152-3: dilution 1:2,000; MBL, USA), anti-Beclin-1 (CST 3495: dilution 1:1,000; Cell Signaling, Danvers, MA, USA); anti-ATG-5 (CST 8540: dilution 1:1,200; Cell Signaling, Danvers, MA, USA); anti-p62 (D5E2, CST 8025: dilution 1:1,500; Cell Signaling, Danvers, MA, USA); antiBax (2D2, CST 89477: dilution 1:1,000; Cell Signaling, Danvers, MA, USA); anti-Bcl-2 (124, CST 15071: dilution 1:1,500; Cell Signaling, Danvers, MA, USA). Finally, the chemiluminescence examination was performed based on the secondary HRP antibody using an exposed film.

\section{Co-localization}

The fixed cells with paraformaldehyde were immunostained using an appropriated antibody after staining with 4',6-diamidino-2-phenylindole. Furthermore, confocal images were obtained with Zeiss 510 META microscope.

\section{Calcium flux}

Cells were dealt with Fluo-3 AM for a record of $\mathrm{Ca}^{2+}$ ions based on the controller of temperature at $37^{\circ} \mathrm{C}$ utilizing the platform for life imaging service (Efringerstrasse 79, 4057 Basel, Switzerland). After washing with HBSS solution, the intensity and location of intracellular Fluo-3 fluorescence were recorded and monitored at 340-380 $\mathrm{nm}$ [29]. The concentration variation of free calcium in cells was represented by the ratio of F340/380 fluorescence intensity, which was the key factor for the cytosolic changes of $\mathrm{Ca}^{2+}$ concentrations [29]. The image and fluorescence were obtained with a fluorescence microscope coupled to a camera, then analyzed using Fluorescence Ratio Imaging Software (version 7.0). A total of 50-100 cells were measured individually in each experiment group, and which were repeated three times.

\section{Statistics}


The data were shown as mean \pm SD (Standard deviation). The differences between the two groups were analyzed with the Student's $t$-test. Kruskal-Wallis ANOVA was used to analyze the abnormally distributed data among groups. SPSS software (version 18.0) was utilized to perform these statistical analyses. $P<$ 0.05 was significant statistically.

\section{Results}

\section{The phenotype of FAM172A knock-out mice}

CHARGE syndrome is a rare disease with a global incidence rate of about $1 / 10,000$, and its clinical manifestations are extremely complex [30]. Because of the complexity of its phenotype, a special naming method is adopted for the syndrome, that is, the famous abbreviation CHARGE is formed with the first letter of the key phenotype, C-Coloboma or cranial nerve abnormality, H-Heart defect, A-Atreia of choanae, R-Retardation of growth and development, G-Genital underdevelopment, E-Ear abnormalities. However, patients with CHARGE syndrome can not exhibit all the phenotypes, because of each phenotype in different patients can be diagnosed until the phenotype is extremely serious [31]. Many scholars believe that the diagnosis of this syndrome requires at least more than phenotypes of the six malformations in patients with CHARGE syndrome, meanwhile the phenotypes must include coloboma and/or atreia of choanae [32, 33].

In this study, our mouse model of FAM172A knock-out $\left(\right.$ FAM172A $\left.{ }^{-/}\right)$was only about half the size and length of wild-type (WT) mice compared with the same-born control mice (Figure 1A-1C). Besides, the mouse models were characterized as having blepharophimosis and short limbs. The right lower limb of this mouse model was absent, and there was no tail. Moreover, our mouse model mice (FAM172A $\left.{ }^{-/}\right)$had significant differences in individual size and length compared with the same-born control WT mice, and their tail was short. Therefore, it indicated the obvious dysgenopathy (Figures 1D and 1E).

\section{ABR threshold assessment and Morris water maze test}

The mouse model with hearing loss was knocked out FAM172A gene, then diagnosed as CHARGE syndrome. Hence, the ABR measurement was used to evaluate hearing thresholds. Consequently, the results of hearing thresholds at frequency $32 \mathrm{kHz}, 16 \mathrm{kHz}$, and $8 \mathrm{kHz}$ in the control group were 20 \pm 2.5 , $23 \pm 2.1$, and $28 \pm 2.9 \mathrm{~dB} \mathrm{SPL}$, respectively. However, the hearing thresholds in the model group increased significantly to $76 \pm 5.8,84 \pm 3.1$, and $73 \pm 2.3 \mathrm{~dB}$ SPL, respectively (Figure $2 \mathrm{~A}$ ).

Furthermore, Morris water maze test was performed for the tasks during the spatial exploration. In control mice, the amount of time spent in the novel arm was not significantly different to the amount of time spent in the familiar arm, indicating that control mice did not distinguish the novel arm.

Interestingly, animals from the model group spent significantly more time than the control group, indicating that the abnormal function of spatial learning in FAM172A deficient animals (Figure 2B). 


\section{Cell morphology in the inner ear of FAM172A-deficient mice}

Analysis of the cochlea in control and model animals (P2) based on whole mount staining with phalloidin (green). It did not suggest the morphological changes in hair cells between the model mice (Figure 3B) and control mice (Figure 3A). Besides, the FAM172A-deficient mice (Figure 3D) showed a diminished number of spiral ganglion cells (Figure $3 \mathrm{E}$ ) in comparison with wild-type mice (Figure $3 \mathrm{C}$ ).

\section{Differential miRNAs and IncRNAs expression analysis}

The differential expression of miRNAs was further valuated in primary SGNs between the model group and control group based on miRNA sequencing. Consequently, there were differentially expressed 18 miRNAs between the two groups, including 15 upregulated expression of miRNAs and three downregulated miRNAs in FAM172A deficient mice (Table 2). Additionally, the relative miR-27a expression in primary SGNs of the model group was significantly enhanced than that in the normal mice (Table 2). 
Table 2

Differentially expressed miRNAs in SGNs between the control mice and FAM $172 \mathrm{~A}^{-/-}$mice.

\begin{tabular}{|lll|}
\hline miRNA & Fold-change (FAM172A ${ }^{-/-} /$Control mice) & $P$-values \\
\hline miR-let-7b & 6.34 & $18.73 \mathrm{E}-03$ \\
\hline miR-125a & 4.57 & $8.59 \mathrm{E}-03$ \\
\hline miR-499a & 4.19 & $6.14 \mathrm{E}-03$ \\
\hline miR-761 & 4.02 & $7.05 \mathrm{E}-03$ \\
\hline miR-99b & 3.64 & $2.57 \mathrm{E}-03$ \\
\hline miR-488 & 3.09 & $4.83 \mathrm{E}-03$ \\
\hline miR-9a & 2.88 & $1.86 \mathrm{E}-03$ \\
\hline miR-93 & 2.73 & $3.56 \mathrm{E}-03$ \\
\hline miR-874 & 2.62 & $5.49 \mathrm{E}-03$ \\
\hline miR-27a & 2.61 & $2.51 \mathrm{E}-03$ \\
\hline miR-4782 & 2.42 & $7.46 \mathrm{E}-03$ \\
\hline miR-30c & 2.38 & $3.73 \mathrm{E}-03$ \\
\hline miR-4700 & 2.33 & $8.34 \mathrm{E}-03$ \\
\hline miR-744 & 2.25 & $1.52 \mathrm{E}-03$ \\
\hline miR-4458 & 2.22 & $9.45 \mathrm{E}-04$ \\
\hline miR-4429 & 0.58 & $3.18 \mathrm{E}-03$ \\
\hline miR-4306 & 0.46 & $2.68 \mathrm{E}-03$ \\
\hline miR-424 & 0.25 & $4.24 \mathrm{E}-03$ \\
\hline
\end{tabular}

Moreover, after a series of screening works on IncRNAs sequencing, the differential IncRNAs expression analysis of primary SGNs between the model group and control group were performed, too. We found ten IncRNAs, including five upregulated and five downregulated IncRNAs with stable expression differences (Table 3). 
Table 3

Differentially expressed IncRNAs in SGNs between the control mice and FAM $172 A^{-/-}$mice.

\begin{tabular}{|lll|}
\hline miRNA & Fold-change (FAM172A ${ }^{-/} /$Control mice) & $P$-values \\
\hline CCAT1 & 4.66 & 0.014 \\
UCA1 & 3.57 & 0.005 \\
RP5-881L22.5 & 3.98 & 0.022 \\
\hline NOS2P3 & 4.21 & 0.005 \\
\hline BC005081 & 4.78 & 0.002 \\
\hline AK055386 & -4.87 & 0.005 \\
\hline AC078941.1 & -4.95 & 0.007 \\
\hline NR_028080.1 & -6.01 & 0.004 \\
\hline RP11-628E19.3 & -6.12 & 0.001 \\
\hline RP11-384P7.7 & -5.57 & 0.012 \\
\hline
\end{tabular}

After screening the lengths, adjacent coding genes, and other multiple conditions of the above ten IncRNAs, then these results show that NR_028080.1, CCAT1, and AK055386 had the full-length sequence in the open database. By querying the NCBI database, it was found that there was no report of NR_028080.1. Furthermore, the analysis of biological informatics confirmed that NR_028080.1 was the transcript coming from FAM172A gene, which was extensively studied by our team. Based on its expression level in SGNs, we named NR_028080.1 as LncRNA-DRSGN (Down-regulated in spiral ganglion neurons).

Furthermore, qRT-PCR experiments were conducted to identify the differential expression of miRNAs and IncRNAs in primary SGNs. These results demonstrated the high expression level of miR-27a (Figure 4A) and low expression level of LncRNA-DRSGN (Figure 4B) in SGNs coming from FAM172A deficient mice than that in the control group. It was in line with the results of sequencing.

\section{LncRNA-DRSGN bound to miR-27a}

Whereafter, two biological informatics software DIANA-LncBase and miRcode, was used to predict the combination between the differential expressed miRNAs and IncRNAs selected from the above sequencing experiments. Then, the results indicated that miR-27a had binding sites of LncRNA-DRSGN (Figure 5A).

Moreover, the overexpression (Figure 5B) and knockdown (Figure 5C) of LncRNA-DRSGN shifted miR-27a expression level. It suggested the targeted relationship between them, then the assay of RNA pull-down 
and dual luciferase reporter assay were conducted to confirm their interaction. According to the assay of dual luciferase reporter gene, the mimics of miR-27a and LncRNA-DRSGN-WT were co-transfected into Neuro 2A cells, the result showed significantly decreased fluorescence (Figure 5D), and it identified LncRNA-DRSGN directly targeted miR-27a. Besides, Ago2 was detected in the mixed extraction of SGNs and LncRNA-DRSGN labeled with biotin according to RNA pull-down assay (Figure 5E), and it suggested the combination between RISC complex and LncRNA-DRSGN. In addition, the high expression level of miR-27a was found in DRSGN-pulled-down pellets based on qRT-PCR experiment (Figure 5F). These results suggested that as a ceRNA, LncRNA-DRSGN could regulate miR-27a.

\section{miR-27a inhibited FAM172A expression in Neuro 2A cells}

It was confirmed that by targeting FAM172A, miR-27a promotes invasion, migration, and proliferation of colorectal cancer [19]. Therefore, the luciferase reporter gene system was further utilized to prove miR-27a straight target FAM172A. Our results demonstrated that 3' UTR luciferase activity of FAM172A downregulated clearly in Neuro 2A cells after treatment with mimics of miR-27a (Figure 6A). Nevertheless, the mutation of FAM172A did not exhibit significant alteration (Figure 6B). Meanwhile, miR-27a did not bind to the 3' UTRs of GRP78/BiP, CHOP, LC3, Beclin-1, ATG-5, p62, Bax, and Bcl-2 (data not shown).

Moreover, the role of miR-27a in FAM172A protein expression was explored. The results demonstrated that miR-27a suppressed FAM172A protein expression in Neuro 2A cells (Figure 6C). In a word, it stated that miR-27a straight regulated the expression of FAM172A mRNA by binding to its 3 '-UTR, and further affected its protein expression level.

LncRNA-DRSGN competed with miR-27a for binding to FAM172A, and participated in the regulation of ER stress-related calcium flux

Through examining the expression levels of ER stress marker protein GRP78 and its key signal transduction pathway protein CHOP, we found that the LncRNA-DRSGN resulted in obviously increased expression levels of FAM172A, but the remarkably decreased of GRP78 and CHOP expression level in Neuro 2A cells. On the contrary, miR-27a caused significantly increased expression levels of GRP78 and $\mathrm{CHOP}$ through suppressing FAM172A expression. However, the above biological function of miR-27a could be reversed by LncRNA-DRSGN (Figure 7A).

The fluorescence intensity of Fluo-3M indicated that the degree of calcium flux, then the higher brightness of Fluo-3M corresponded to the stronger calcium flux, but the lower intensity of fluorescent images accounted for the opposite results. Moreover, the expression of calreticulin demonstrated its cellular location in ER. Furthermore, through intracellular detection experiments of calcium flux, it was declared that LncRNA-DRSGN effectively inhibited intracellular calcium flux $(P<0.01)$. On the contrary, miR-27a resulted in a significant promotion of intracellular calcium flux $(P<0.01)$. However, the calcium flux induced by miR-27a could be reversed by LncRNA-DRSGN (Figure 7B). 
The laser confocal microscope was further used to detect intracellular calcium flux, and the ER localization marker of calreticulin was used as an internal reference. The results illustrated that LncRNADRSGN restrained the protein expression of ER-stress pathway resulted in a significant decrease of intracellular calcium flux $(P<0.01)$. On the contrary, miR-27a markedly promoted intracellular calcium flux $(P<0.01)$ (Figure 7C).

These results indicated that LncRNA-DRSGN competes with miR-27a mediated by FAM172A and participated in the regulation of the calcium flux associated with ER stress process of Neuro 2A cells.

LncRNA-DRSGN competed with miR-27a for binding to FAM172A, and participated in regulating autophagy of Neuro 2A cells

Over-expression or interference with the expression of FAM172A were induced utilizing LncRNA-DRSGN and/or miR-27a with the purpose of confirming whether LncRNA-DRSGN competed with miR-27a for binding to FAM172A, and then regulated the autophagy process of Neuro 2A cells. Through examining of the autophagy marker protein LC-3 and its subtypes LC-3囚 and LC-3\ expression levels, we found that

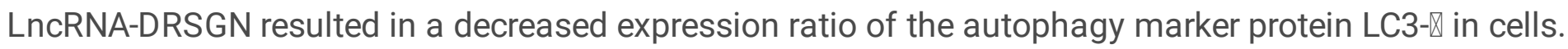
On the contrary, interference with the expression of FAM172A with the mimics of miR-27a made for a visible increased expression ratio of the autophagy marker protein LC3-II in Neuro 2A cells (Figures 8A and $8 \mathrm{~B})$.

Meanwhile, LncRNA-DRSGN prohibited miR-27a and induced over-expression of FAM172A resulted in decreased expression of the key regulatory protein complexes of autophagy, Beclin-1, ATG-5 and p62 in Neuro 2A cells. In addition, LncRNA-DRSGN inhibited the expression level of the apoptosis-promoting protein Bax, and promoted the expression of the apoptosis-inhibiting protein Bcl-2. However, miR-27a could induce all opposite affections (Figures 8A and 8B).

Further application of laser confocal microscopy was utilized to detect the autophagy status of cells, the results stated that through inhibited miR-27a, LncRNA-DRSGN caused overexpression of FAM172A, then restrained the autophagy process of Neuro 2A cells. However, by inhibiting the expression of FAM172A with miR-27a could promote the autophagy process of Neuro 2A cells (Figure $8 \mathrm{C}$ ). Therefore, these results proved that LncRNA-DRSGN competed with miR-27a for binding to FAM172A and participated in regulating the autophagy process of Neuro $2 \mathrm{~A}$ cells.

\section{Discussion}

Hearing loss is one of the most common disabilities in the world today, and not only seriously affects the QOL (Quality of life) of patients, but also brings a heavy burden to society [34]. The global economic burden caused by hearing loss is as high as 750 billion US dollars each year. WHO calculates and reports that the government can get a return of US\$16 for every US\$1 invested in hearing loss prevention and health care. Therefore, prevention and health care of hearing loss has important social significance and considerable cost-effectiveness [35]. Sensorineural Hearing Loss is caused by a variety of damage 
sources, including mutations in deafness genes [36-38], aging [39], noise exposure, chronic cochlear infections, and ototoxic drugs [40-43].

At present, the treatment of hearing loss is very limited. Although hearing aids and cochlear implants can improve some symptoms of hearing loss, but these treatments cannot make for complete healing of the underlying disease, and their efficacy depends on the quantity and quality of residual hair cells or spiral ganglion neurons [44]. Hair cells and spiral ganglion neurons are important sensors for auditory function. The cochlear hair cells and spiral ganglion neurons of adult mammals and humans cannot effectively spontaneously regenerate after degeneration, apoptosis, and death. Antagonizing the damage and death of hair cells and spiral ganglion neurons is the core content of hearing protection [45].

In this study, our mouse model with knock-out FAM172A gene $\left(\right.$ FAM172 $\left.A^{-/}\right)$had significant differences in individual size and length, even dysgnosia, and hearing loss compared with the same-born control WT mice. Moreover, FAM172A deficient mice had a low number of SGNs and high ABR thresholds. Therefore, our mouse model with hearing loss, growth retardation, and abnormal eye development could be diagnosed as CHARGE syndrome.

The current known research on the pathogenesis of CHARGE syndrome has only confirmed the only genetic factor related to the heterozygous mutation of CHD7 (Chromodomain helicase DNA-binding protein 7) [46]. However, according to the currently used diagnostic criteria, up to about $30 \%$ of patients have not detected CHD7 positive mutations. The CHARGE syndrome models of CHD7 mutant mice obtained by experimental studies in recent years all have otitis media, and otitis media has adverse effects on hearing and development of the auditory nerve, even the development of the central nervous system. Therefore, this model is not stable enough, and it has caused serious model interference to clarify the pathogenesis of CHARGE syndrome [47]. Therefore, it is still extremely difficult to clarify the pathogenesis of CHARGE [48].

About $80 \%$ of patients with CHARGE syndrome have ocular defects, including ocular defects, retinal or optic neuropathy, glaucoma, and cataracts. The incidence of posterior nostril atresia is $51-100 \%$, of which $65 \%$ are bilateral atresia and $29 \%$ are left unilateral atresia [49]. More than $90 \%$ of cases have growth and development disorders, such as low birth weight, postnatal growth retardation, and short stature. Almost $100 \%$ of patients have mental retardation, and $68 \%-75 \%$ of patients have small penis, cryptorchidism, vaginal dysplasia, bicornuate uterus, uterine dysplasia and other gonad development [50]. More than $80 \%$ of patients have lower ears, ear deformities and/or deafness, and most of them are sensorineural deafness. Cardiovascular damage accounts for $60 \%-88 \%$ of all patients. Patients with CHARGE syndrome are often accompanied by cardiovascular malformations, including Tetralogy of Fallot, patent ductus arteriosus, endocardial cushion defect, double right ventricular outlet, atrium or ventricular septum defects, right aortic arch, aortic transection, abnormal subclavian artery, left ventricular dysplasia, etc. [51]. Cyran believes that there are many types of cardiovascular malformations in this disease, but no type of malformation is specific. Lin believes that the cardiovascular malformations of patients with this disease are conical trunk and aortic arch malformations. The former includes Tetralogy 
of Fallot, right ventricular double outlet, and trunk arteries, accounting for $42 \%$, the latter includes aortic arch interruption, aortic arch dysplasia and subclavian artery malformation, etc., accounting for $36 \%$ [47]. Lin believes that this particular type of cardiovascular malformation has a certain degree of specificity. In addition to the above six major deformities, other associated deformities reported in the literature include: small jaw, cleft lip and palate, facial paralysis, dysphagia, esophagotracheal fistula or atresia, anal stenosis or atresia, renal deformity, small head, small mouth, short in humans, the fifth finger is short, the body's resistance is poor, epilepsy, microcephaly, abnormal pituitary gland, and weakened immune system. The proportion of patients with this syndrome diagnosed with ocular and ear malformations and cardiovascular defects is not low, but fewer patients with posterior nostril atresia [47-52]. The incidence of posterior nostril atresia in CHARGE syndrome is quite high, which is one of the diagnostic features. Many scholars believe that the diagnosis of this syndrome requires at least three or more phenotypes of six malformations, which must include posterior nostril atresia and/or eye disability [50-52].

In the previous research work of our research group, we successfully prepared a knockout mouse model of FAM172A gene using CRISPR-Cas9 system and found that the mouse model exhibited abnormal hearing, growth retardation, abnormal eye development, and dysgnosia. The other phenotypes were in line with the phenotypes and diagnosis of CHARGE syndrome. Besides, our mouse model of FAM172A $\mathrm{A}^{(-/)}$ did not have otitis media. Therefore, our work provides a good animal model for the research on the pathogenesis, diagnosis, and treatment of CHARGE syndrome.

Research reports on familial cases of CHARGE syndrome confirm that it is characterized by widespread clinical variability, and the phenotype transferred to the next generation from parents with severe symptoms is often mild or even asymptomatic [47-49]. Such a wide range of phenotypic manifestations has led to the revision of the diagnostic criteria for CHARGE syndrome many times in the past decade [48]. Many abnormal phenotypes of CHARGE syndrome may be life-threatening, so about $30 \%$ of children die before five years of age [49]. The survival period and QOL of children are difficult to determine, but they are closely related to the age of diagnosis. This is not only because of the diversity of its clinical manifestations, but also because of the collection of important disease cases related to the syndrome that still cannot be explained genetically [50]. Therefore, clarifying its pathogenesis, exploring reliable diagnostic methods, developing effective methods, and drugs for the treatment of CHARGE syndrome have become one of the key scientific issues in the field of rare disease research.

In our previous work, we found the potent binding activity between FAM172A protein and $\mathrm{Ca}^{2+}$ ions, and the significantly downregulated the expression of FAM172A in ER stress situation of HepG2 cells induced by tunicamycin [17]. However, the intracellular calcium signaling pathways are referred to a variety of cellular biological functions, such as growth, apoptosis, differentiation, and autophagy [61]. Moreover, the in-depth and comprehensive researches involved in the interaction mechanism between apoptosis and autophagy must take breakthrough on the treatment and cognition of various diseases [53,54].

Therefore, further investigation on the pathogenesis of our mouse model was performed. Epigenetic modifications are now known to significantly contribute to the biological function of nerve cells [55].

Page 15/31 
Consequently, the next-genesequencing experiments of noncoding RNAs were conducted utilizing the primary SGNs, differential microRNAs and IncRNA were found and identified, including miR-27a and LnCRNA-DRSGN. In addition, our results further confirmed that miR-27a had binding sites with LncRNADRSGN, and LncRNA-DRSGN could regulate miR-27a as a ceRNA. At the mean time, miR-27a inhibited FAM172A expression in Neuro 2A cells.

Our previous experimental data demonstrated the biological functions of FAM172A, which played a suppressor role in hepatocytes associated with ER stress $[17,19]$. Furthermore, our study proved that LncRNA-DRSGN competed with miR-27a for binding to FAM172A and participated in the regulation of ER stress-related calcium flux.

According to the different regulation methods of apotosis and autophagy, the interaction can be roughly summarized into three types: cooperative relationships, confrontation relationship, and promotion relationships [56-60]. The multiple interaction modes between autophagy and apoptosis must have common signaling pathways and regulatory proteins, which researchers call interaction regulators [61]. Hence, overexpression and interference with the expression of FAM172A were induced utilizing LncRNADRSGN and/or miR-27a with the purpose of confirming that LncRNA-DRSGN competed with miR-27a for binding to FAM172A, and then regulated the autophagy process of Neuro $2 \mathrm{~A}$ cells.

In conclusion, our work illustrated that LnCRNA-DRSGN competed with miR-27a for binding to FAM172A and participated in regulating endoplasmic reticulum stress-related calcium flux and autophagy process of SGN degeneration in CHARGE syndrome.

\section{Declarations}

\section{Ethics approval and consent to participate}

This work was approved by the Experimental Animal Ethics Committee of Kunming University of Science and Technology (Kunming, Yunnan Province, China). and the reference number was 2015-0431.

\section{Consent for publication}

Not applicable.

\section{Availability of data and materials}

The data used to support the findings of this study are included within the article.

\section{Competing interests}

The authors declare that they have no competing interests.

\section{Funding}


This work was supported by grants from the National Natural Science Foundation of China (No. 30600524 and 81341067), the National Natural Science Foundation of Guangdong Province, China (No. 2017A030313510 and 2019A1515011099), Guangzhou Science and Technology Plan Projects (No. 201904010032). The study sponsors had no involvement in the work.

\section{Authors' contributions}

$X B C, B Z L$, and JQZ contributed to the conception of the study; XBC and BZL contributed significantly to performing these experiments; XBC, JHP, CF, YFG, SMG, LL, DWL, and JQZ performed the data analyses and wrote the manuscript; XBC, BZL, AZT, and JQZ helped perform the analysis with constructive discussions.

\section{Acknowledgements}

Not applicable.

\section{References}

1. Clark GM (2013) The multichannel cochlear implant for severe-to-profound hearing loss. Nat Med 19:1236-1239

2. Nayagam BA, Muniak MA, Ryugo DK (2011) The spiral ganglion: connecting the peripheral and central auditory systems. Hear Res 278:2-20

3. Géléoc GS, Holt JR (2014) Sound strategies for hearing restoration. Science 344:1241062

4. Liu W, Wang X, Wang M, Wang H (2019) Protection of Spiral Ganglion Neurons and Prevention of Auditory Neuropathy. Adv Exp Med Biol 1130:93-107

5. Richter CP, Tan XD (2014) Photons and Neurons. Hear Res 0:72-88

6. Lan Y, Tao Y, Wang Y, Ke J, Yang Q, Liu X, Su B, Wu Y, Lin CP, Zhong G (2020) Recent development of AAV-based gene therapies for inner ear disorders. Gene Ther 27:329-337

7. Bergman JE, Janssen N, Hoefsloot LH, Jongmans MC, Hofstra RM, van Ravenswaaij-Arts CM (2011) CHD7 mutations and CHARGE syndrome: the clinical implications of an expanding phenotype. $\mathrm{J}$ Med Genet 48:334-342

8. Levine B, Kroemer G (2019) Biological Functions of Autophagy Genes: A Disease Perspective. Cell $176: 11-42$

9. Kim KH, Lee MS (2014) Autophagy-a key player in cellular and body metabolism. Nat Rev Endocrinol 10:322-337

10. Rubinsztein DC, Mariño G, Kroemer G (2011) Autophagy and aging Cell 146:682-695

11. Magariños M, Pulido S, Aburto MR, de Iriarte Rodríguez R, Varela-Nieto I (2017) Autophagy in the Vertebrate Inner Ear. Front Cell Dev Biol 5:56

12. Scherz-Shouval R, Elazar Z (2007) ROS, mitochondria and the regulation of autophagy. Trends Cell Biol 17:422-427 
13. Baba M, Tomonaga S, Suzuki M, Gen M, Takeda E, Matsuura A, Kamada Y, Baba N (2019) A nuclear membrane-derived structure associated with Atg8 is involved in the sequestration of selective cargo, the Cvt complex, during autophagosome formation in yeast. Autophagy 15:423-437

14. Hori I, Otomo T, Nakashima M, Miya F, Negishi Y, Shiraishi H, Nonoda Y, Magara S, Tohyama J, Okamoto N, Kumagai T, Shimoda K, Yukitake Y, Kajikawa D, Morio T, Hattori A, Nakagawa M, Ando N, Nishino I, Kato M, Tsunoda T, Saitsu H, Kanemura Y, Yamasaki M, Kosaki K, Matsumoto N, Yoshimori T, Saitoh S (2017) Defects in autophagosome-lysosome fusion underlie Vici syndrome, a neurodevelopmental disorder with multisystem involvement. Sci Rep 7:3552

15. Dubois C, Kondratskyi A, Bidaux G, Noyer L, Vancauwenberghe E, Farfariello V, Toillon RA, Roudbaraki M, Tierny D, Bonnal JL, Prevarskaya N (2020) Vanden Abeele F. Co-targeting Mitochondrial Ca ${ }^{2+}$ Homeostasis and Autophagy Enhances Cancer Cells' Chemosensitivity. iScience ; 23: 101263

16. Yorimitsu T, Klionsky DJ (2007) Endoplasmic reticulum stress: a new pathway to induce autophagy. Autophagy 3:160-162

17. Shen W, Feng Z, Wang P, Zhang J (2017) FAM172A controls endoplasmic reticulum (ER) stress related to NF-KB signaling pathway in hepatocellular carcinoma. RSC Adv 7:51870-51878

18. Mohammadinejad R, Moosavi MA, Tavakol S, Vardar D, Hosseini A, Rahmati M, Dini L, Hussain S, Mandegary A, Klionsky DJ (2019) Necrotic, apoptotic and autophagic cell fates triggered by nanoparticles. Autophagy 15:4-33

19. Liu W, Qian K, Wei X, Deng H, Zhao B, Chen Q, Zhang J, Liu H (2017) miR-27a promotes proliferation, migration, and invasion of colorectal cancer by targeting FAM172A and acts as a diagnostic and prognostic biomarker. Oncol Rep 37:3554-3564

20. Cong L, Ran FA, Cox D, Lin S, Barretto R, Habib N, Hsu PD, Wu X, Jiang W, Marraffini LA, Zhang F (2013) Multiplex genome engineering using CRISPR/Cas systems. Science 339:819-823

21. Ran FA, Hsu PD, Wright J, Agarwala V, Scott DA, Zhang F (2013) Genome engineering using the CRISPR-Cas9 system. Nat Protoc 8:2281-2308

22. Kim HJ, Lee HJ, Kim H, Cho SW, Kim JS (2009) Targeted genome editing in human cells with zinc finger nucleases constructed via modular assembly. Genome Res 19:1279-1288

23. Flores M, Morales L, Gonzaga-Jauregui C, Dominguez-Vidana R, Zepeda C, Yanez O, Gutiérrez M, Lemus T, Valle D, Avila MC, Blanco D, Medina-Ruiz S, Meza K, Ayala E, García D, Bustos P, González V, Girard L, Tusie-Luna T, Dávila G, Palacios R (2007) Recurrent DNA inversion rearrangements in the human genome. Proc Natl Acad Sci USA 104:6099-6106

24. Cediel R, Riquelme R, Contreras J, Diaz A, Varela-Nieto I (2006) Sensorineural hearing loss in insulinlike growth factor I-null mice: a new model of human deafness. Eur J Neurosci 23:587-590

25. Brody DL, Holtzman DM (2005) Morris water maze search strategy analysis in PDAPP mice before and after experimental traumatic brain injury. Exp Neurol 197:330-340

26. Ruediger S, Spirig D, Donato F, Caroni $P$ (2012) Goal-oriented searching mediated by ventral hippocampus early in trial-and-error learning. Nat Neurosci 15:1563-1571 
27. Bako P, Bassiouni M, Eckhard A, Gerlinger I, Frick C, Löwenheim H, Müller M (2015) Methyl methacrylate embedding to study the morphology and immunohistochemistry of adult guinea pig and mouse cochleae. J Neurosci Methods 254:86-93

28. Kozomara A, Griffiths-Jones S (2011) miRBase: integrating microRNA annotation anddeepsequencing data. Nucleic Acids Res 39:D152-157

29. Rijkers GT, Justement LB, Griffioen AW, Cambier JC (1990) Improved method for measuring intracellular $\mathrm{Ca}^{2+}$ with fluo-3. Cytometry 11:923-927

30. Hsu P, Ma A, Wilson M, Williams G, Curotta J, Munns CF, Mehr S (2014) CHARGE syndrome: A review. J Paediatr Child Health 50:504-511

31. Zentner GE, Layman WS, Martin DM, Scacheri PC (2010) Molecular and phenotypic aspects of CHD7 mutation in CHARGE syndrome. Am J Med Genet A 152:674-686

32. Vissers LE, van Ravenswaaij CM, Admiraal R, Hurst JA, de Vries BB, Janssen IM, van der Vliet WA, Huys EH, de Jong PJ, Hamel BC, Schoenmakers EF, Brunner HG, Veltman JA, van Kessel AG (2004) Mutations in a new member of the chromodomain gene family cause CHARGE syndrome. Nat Genet 36:955-957

33. Korver AM, Smith RJ, Van Camp G, Schleiss MR, Bitner-Glindzicz MA, Lustig LR, Usami SI, Boudewyns AN (2017) Congenital hearing loss. Nat Rev Dis Primers 3:16094

34. Lieu JEC, Kenna M, Anne S, Davidson L (2020) Hearing Loss in Children: A Review. JAMA 324:21952205

35. Cunningham LL, Tucci DL (2017) Hearing Loss in Adults. N Engl J Med 377:2465-2473

36. Azaiez H, Booth KT, Ephraim SS, Crone B, Black-Ziegelbein EA, Marini RJ, Shearer AE, Sloan-Heggen CM, Kolbe D, Casavant T, Schnieders MJ, Nishimura C, Braun T, Smith RJH (2018) Genomic Landscape and Mutational Signatures of Deafness-Associated Genes. Am J Hum Genet 103:484497

37. Booth KT, Ghaffar A, Rashid M, Hovey LT, Hussain M, Frees K, Renkes EM, Nishimura CJ, Shahzad M, Smith RJ, Ahmed Z, Azaiez H, Riazuddin S (2020) Novel loss-of-function mutations in COCH cause autosomal recessive nonsyndromic hearing loss. Hum Genet 139:1565-1574

38. Kokotas H, Grigoriadou M, Korres GS, Ferekidou E, Giannoulia-Karantana A, Kandiloros D, Korres S, Petersen MB (2010) Are GJB2 mutations an aggravating factor in the phenotypic expression of mitochondrial non-syndromic deafness?J Hum Genet; 55):265-269

39. Loughrey DG, Kelly ME, Kelley GA, Brennan S, Lawlor BA (2018) Association of Age-Related Hearing Loss With Cognitive Function, Cognitive Impairment, and Dementia: A Systematic Review and Metaanalysis. JAMA Otolaryngol Head Neck Surg 144:115-126

40. Korver AM, Smith RJ, Van Camp G, Schleiss MR, Bitner-Glindzicz MA, Lustig LR, Usami SI, Boudewyns AN (2017) Congenital hearing loss. Nat Rev Dis Primers 3:16094

41. Lieu JEC, Kenna M, Anne S, Davidson L (2020) Hearing Loss in Children: A Review. JAMA 324:21952205 
42. Cunningham LL, Tucci DL (2017) Hearing Loss in Adults. N Engl J Med 377:2465-2473

43. Smith RJ, Bale JF Jr, White KR (2005) Sensorineural hearing loss in children. Lancet 365:879-890

44. Moser T, Starr A (2016) Auditory neuropathy-neural and synaptic mechanisms. Nat Rev Neurol 12:135-149

45. Sun S, Babola T, Pregernig G, So KS, Nguyen M, Su SM, Palermo AT, Bergles DE, Burns JC, Müller U (2018) Hair Cell Mechanotransduction Regulates Spontaneous Activity and Spiral Ganglion Subtype Specification in the Auditory System. Cell 174:1247-1263

46. Vissers LE, van Ravenswaaij CM, Admiraal R, Hurst JA, de Vries BB, Janssen IM, van der Vliet WA, Huys EH, de Jong PJ, Hamel BC, Schoenmakers EF, Brunner HG, Veltman JA, van Kessel AG (2004) Mutations in a new member of the chromodomain gene family cause CHARGE syndrome. Nat Genet 36:955-957

47. Tian C, Yu H, Yang B, Han F, Zheng Y, Bartels CF, Schelling D, Arnold JE, Scacheri PC, Zheng QY (2012) Otitis media in a new mouse model for CHARGE syndrome with a deletion in the CHD7 gene. PLoS ONE 7:e34944

48. Hale CL, Niederriter AN, Green GE, Martin DM. Response to correspondence to Hale et al (atypical phenotypes associated with pathogenic $\mathrm{CHD} 7$ variants and a proposal for broadening CHARGE syndrome clinical diagnostic criteria. Am J Med Genet A 2016) 170(12): 3367-3368

49. Delahaye A, Sznajer $Y$, Lyonnet $S$, Elmaleh-Bergès $M$, Delpierre I, Audollent $S$, Wiener-Vacher $S$, Mansbach AL, Amiel J, Baumann C, Bremond-Gignac D, Attié-Bitach T, Verloes A, Sanlaville D (2007) Familial CHARGE syndrome because of $\mathrm{CHD} 7$ mutation: Clinical intra- and interfamilial variability. Clin Genet 72:112-121

50. Jongmans MC, Hoefsloot LH, van der Donk KP, Admiraal RJ, Magee A, van de Laar I, Hendriks Y, Verheij JB, Walpole I, Brunner HG, van Ravenswaaij (2008) CM.Familial CHARGE syndrome and the CHD7 gene: A recurrent missense mutation, intrafamilial recurrence and variability. Am J Med Genet A $146: 43-50$

51. Lalani SR, Safiullah AM, Fernbach SD, Harutyunyan KG, Thaller C, Peterson LE, McPherson JD, Gibbs RA, White LD, Hefner M, Davenport SL, Graham JM, Bacino CA, Glass NL, Towbin JA, Craigen WJ, Neish SR, Lin AE, Belmont JW (2006) Spectrum of CHD7 mutations in 110 individuals with CHARGE syndrome and genotype-phenotype correlation. Am J Hum Genet 78(2):303-314

52. Zentner GE, Layman WS, Martin DM, Scacheri PC (2010) Molecular and phenotypic aspects of CHD7 mutation in CHARGE syndrome. Am J Med Genet A 152:674-686

53. Ueasilamongkol P, Khamphaya T, Guerra MT, Rodrigues MA, Gomes DA, Kong Y, Wei W, Jain D, Trampert DC, Ananthanarayanan M, Banales JM, Roberts LR, Farshidfar F, Nathanson MH, Weerachayaphorn J (2020) Type 3 Inositol 1,4,5-Trisphosphate Receptor Is Increased and Enhances Malignant Properties in Cholangiocarcinoma. Hepatology 71:583-599

54. Larabi A, Barnich N, Nguyen HTT (2020) New insights into the interplay between autophagy, gut microbiota and inflammatory responses in IBD. Autophagy 16:38-51 
55. Farrelly LA, Thompson RE, Zhao S, Lepack AE, Lyu Y, Bhanu NV, Zhang B, Loh YE, Ramakrishnan A, Vadodaria KC, Heard KJ, Erikson G, Nakadai T, Bastle RM, Lukasak BJ, Zebroski H 3rd, Alenina N, Bader M, Berton O, Roeder RG, Molina H, Gage FH, Shen L, Garcia BA, Li H, Muir TW, Maze I (2019) Histone serotonylation is a permissive modification that enhances TFIID binding to H3K4me3. Nature 567:535-539

56. Ryter SW, Mizumura K, Choi AM (Theimpact of autophagy on cell death modalities. Int J Cell Biol 2014) ; 2014: 502676

57. Jing K, Lim K (2012) Why is autophagyimportant in human diseases? Exp Mol Med 44:69-72

58. Gump JM, Thorburn A (2011) Autophagy andapoptosis-what is the connection? Trends Cell Biol 21:387-392

59. Su M, Mei Y, Sinha S (Role of thecrosstalk between autophagy and apoptosis in cancer. J Oncol 2013) ; 2013:1027-1035

60. Mariño G, Niso-Santano M, Baehrecke EH et al (2014) Baehrecke Self-consumption: the interplay of autophagyand apoptosis. Nat Rev Mol Cell Biol 15:81-94

61. Saita S, Shirane M, Nakayama KI et al (2013) Selective escape of proteins from the mitochondria during mitophagy. Nat Commun 4:1410

\section{Figures}
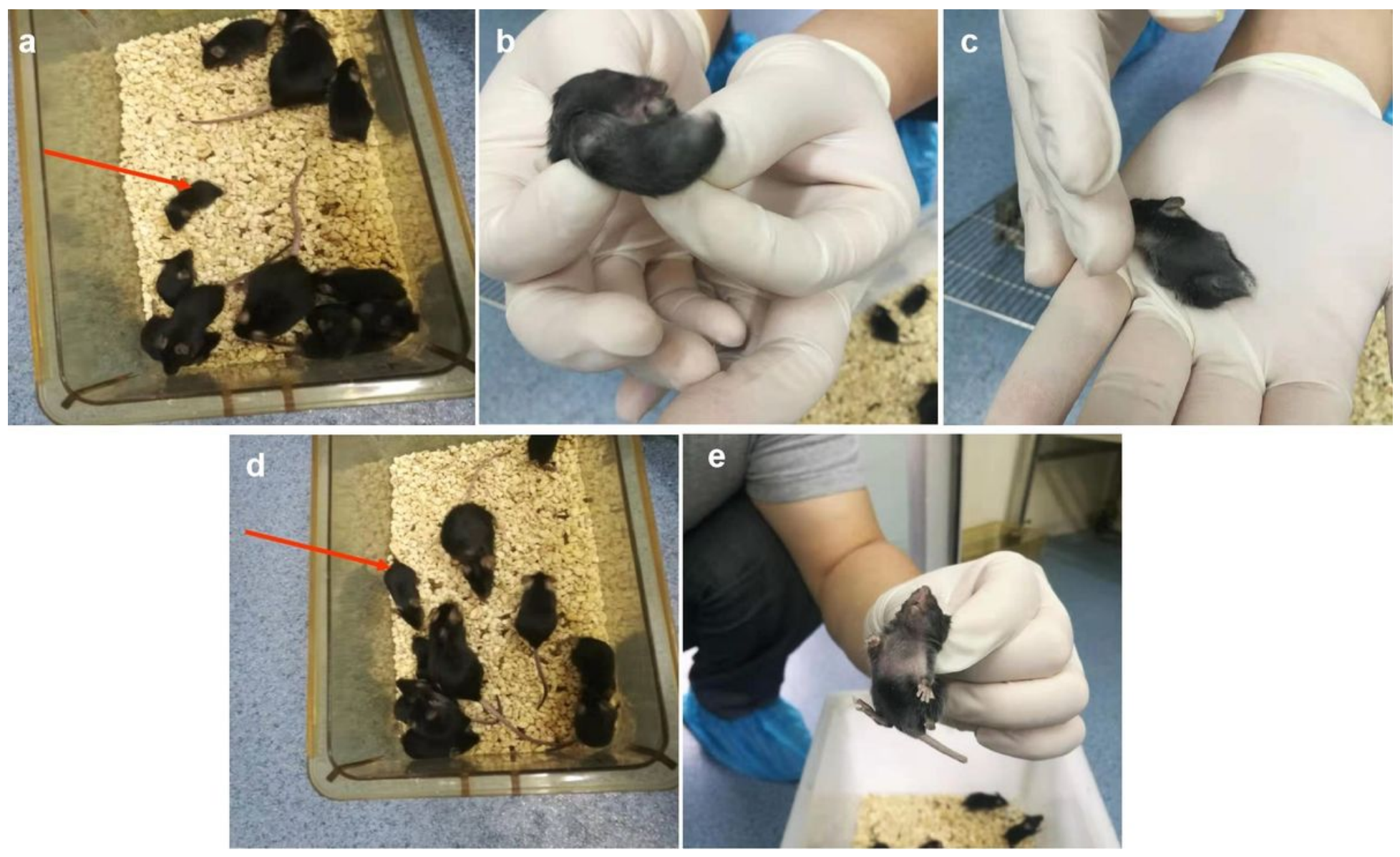


\section{Figure 1}

\section{The phenotype of FAM172A knock-out mice.}

In this study, our model mouse of FAM172A knockout $\left(\right.$ FAM172 $\left.\mathrm{A}^{-/-}\right)$was only about half the size and length of wild-type (WT) mice compared with the same-born control mice (A-C). Besides, the model mouse of CHARGE syndrome had no split eyes and short limbs, at the mean time the right lower limb was absent, but there was no tail. Moreover, our model mice of CHARGE syndrome (FAM172A ${ }^{-/-}$) had significant differences in individual size and length compared with the same-born WT mice, and the tail was short, it indicated developmental delay (D and 1E). (The red arrow showed the model mice of CHARGE syndrome.) 
a

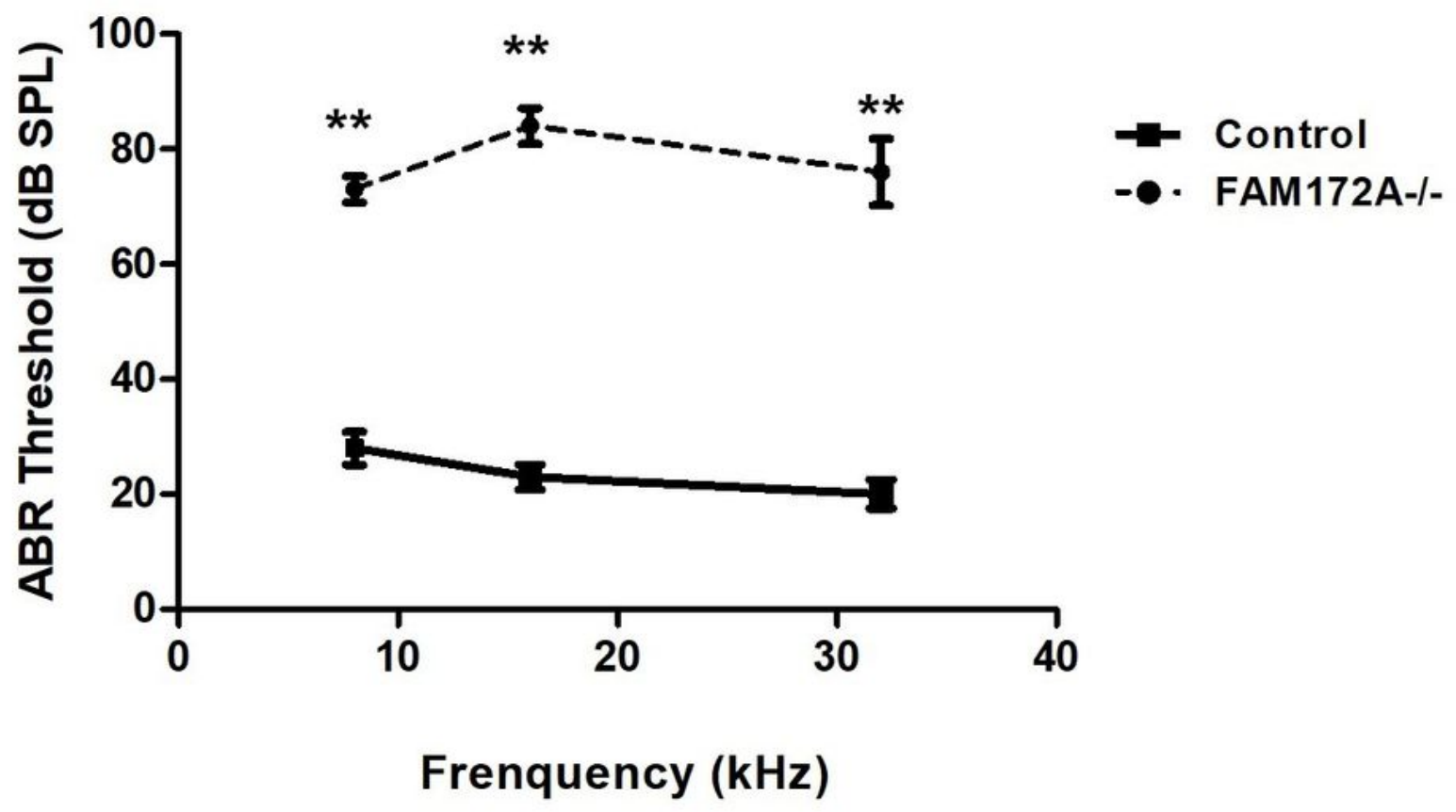

b

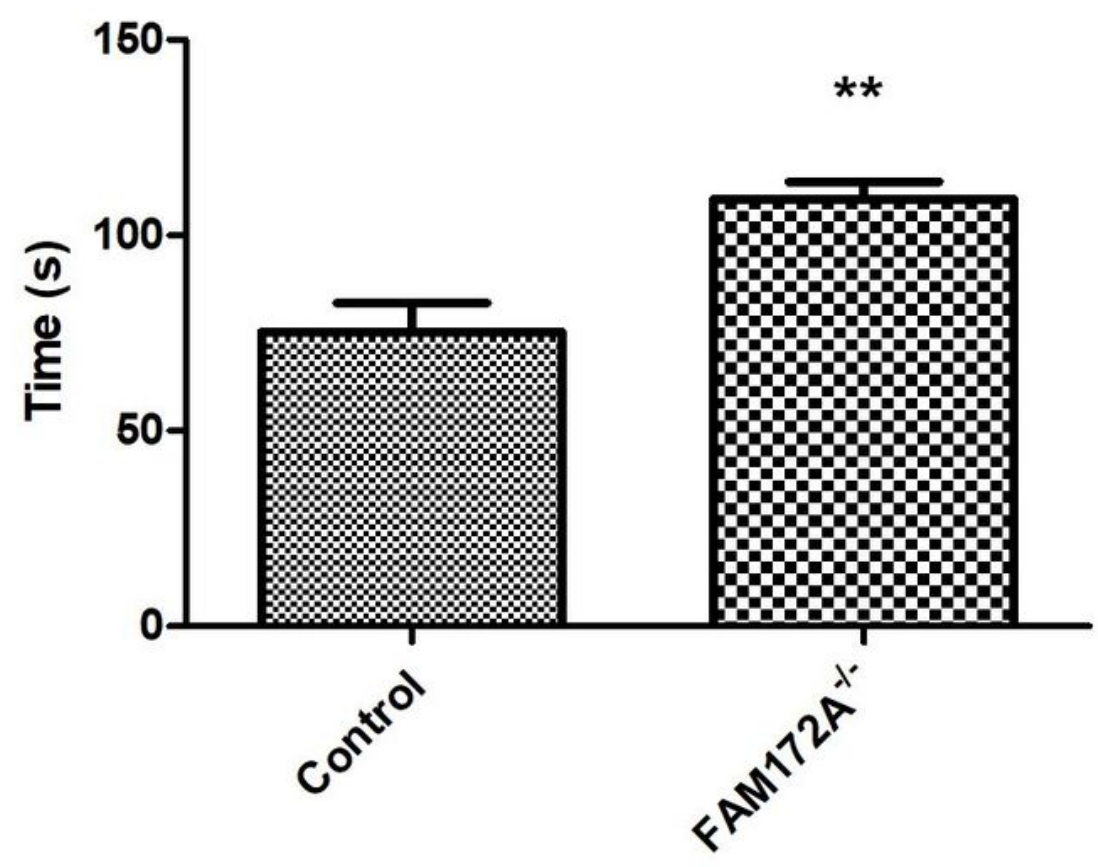

Figure 2

The ABR thresholds assessment.

To confirm hearing loss in the CHARGE syndrome model group, hearing thresholds were evaluated with measurement of $A B R$. The hearing thresholds at 8,16 , and $32 \mathrm{kHz}$ in the control group were $28 \pm 2.9$, $23 \pm 2.1$, and $20 \pm 2.5 \mathrm{~dB}$ SPL, respectively. But, the hearing thresholds in the CHARGE syndrome model 
group significantly increased to $73 \pm 2.3,84 \pm 3.1$, and $76 \pm 5.8 \mathrm{~dB} \mathrm{SPL}$, respectively $(\mathrm{n}=5 ; P<0.01)$. Moreover, the task of Morris water-maze test was performed, too (B). The animals from model group spent significantly more time than the control group,
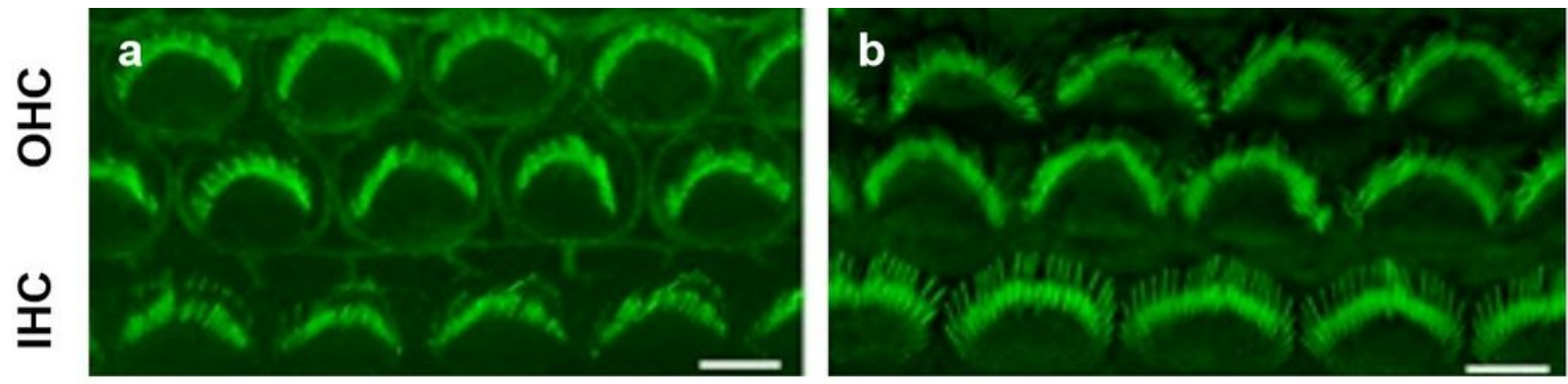

\section{Phalloidin}
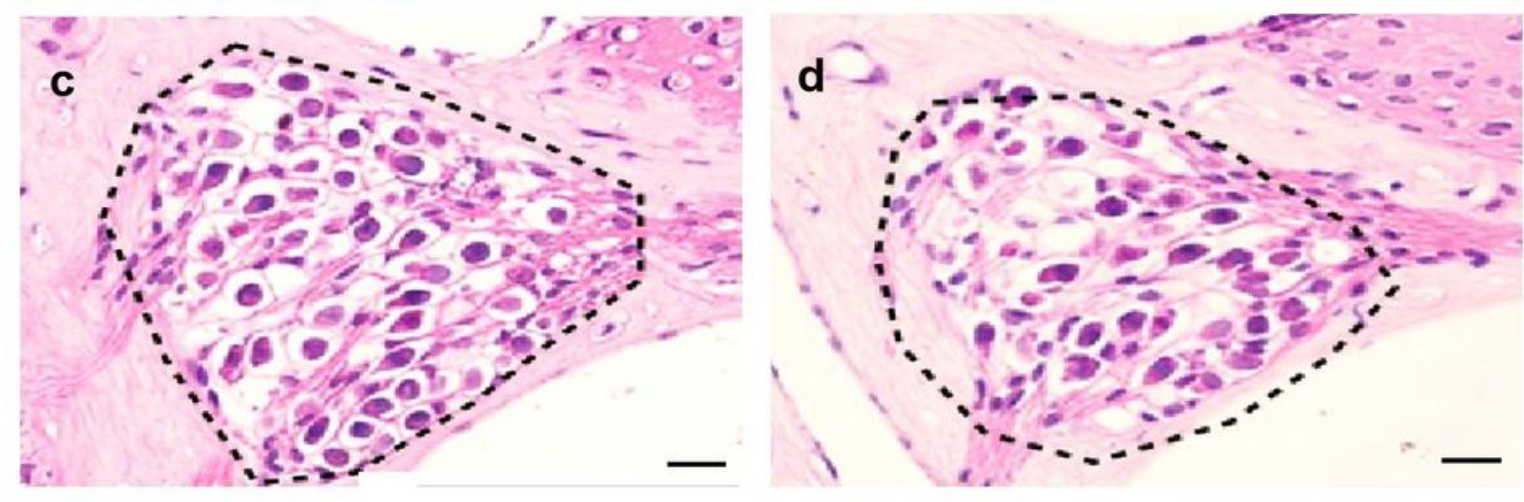

e

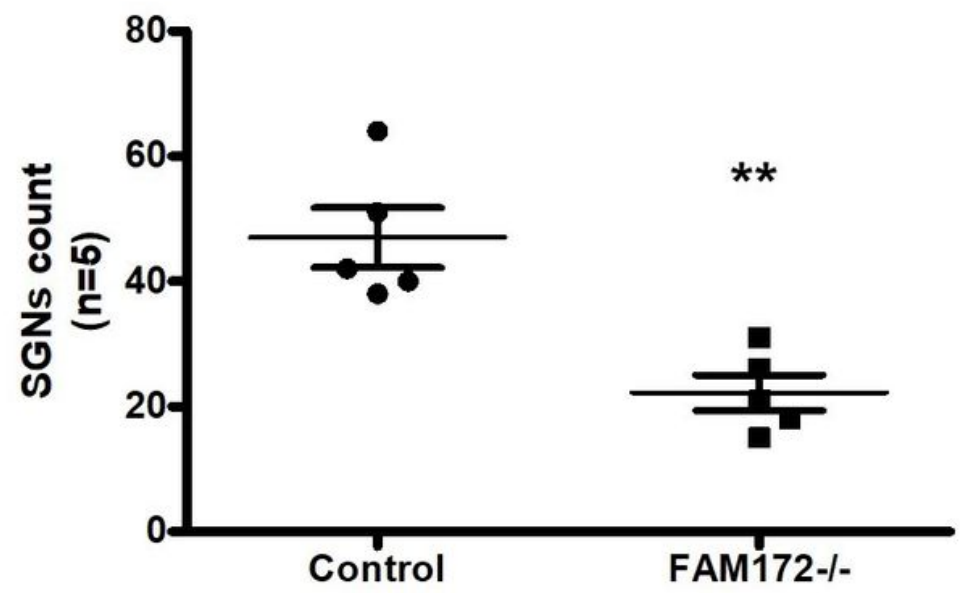

Figure 3

Hair cell morphology and SGNs count. 
Analysis of the cochlea in control mice and model animals (P2) by whole mount staining with phalloidin (green). It did not suggest the morphological changes in hair cells between the model mice (Figure B) and control mice (Figure A). (Scale bars: $5 \mu \mathrm{m}$ )

Besides, the FAM172A-deficient mice (D) showed a diminished number of spiral ganglion cells $(E)(n=5$; $P<0.01$ ) in comparison with the wild-type control mice (C). (Scale bars: $100 \mu \mathrm{m}$ )

a

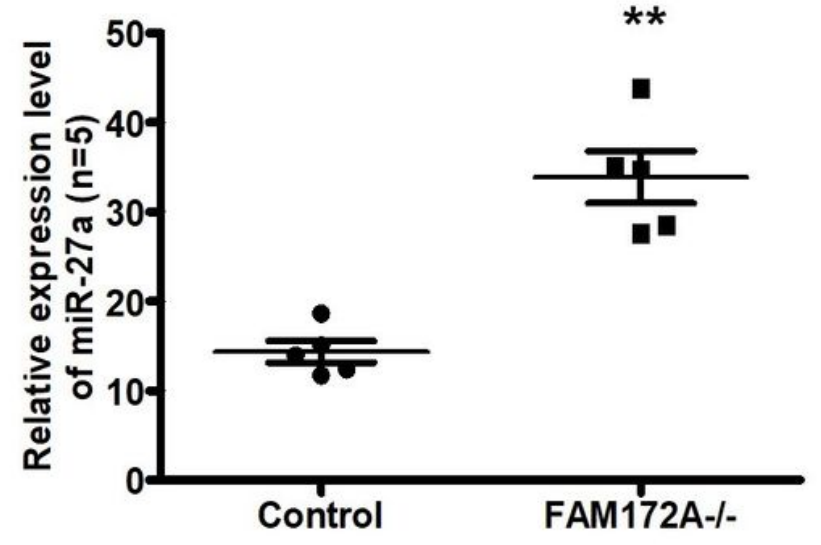

b

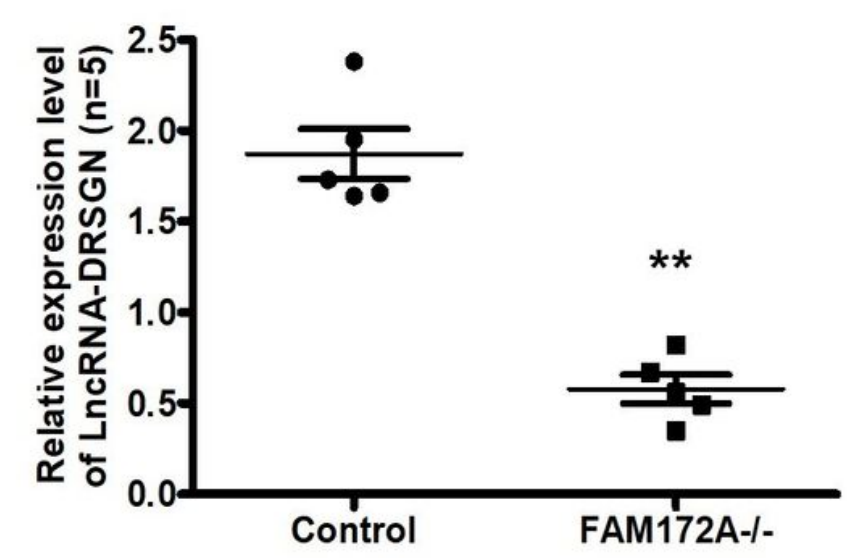

Figure 4

qRT-PCR experiments.

Furthermore, the qRT-PCR experiments were conducted to identify the above differential expression of miRNAs and IncRNAs in primary SGNs. These results demonstrated the high expression level of miR-27a (A) and low expression level of LncRNA-DRSGN (B) in SGNs of FAM172A deficient mice than control group. $(\mathrm{n}=5 ; * \star *<0.01)$ 
a

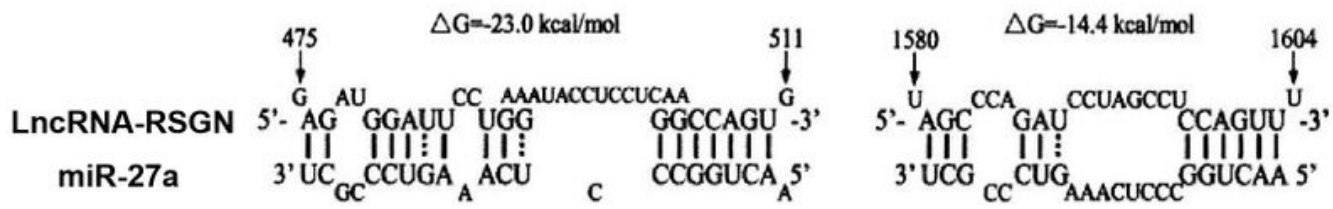

b

c
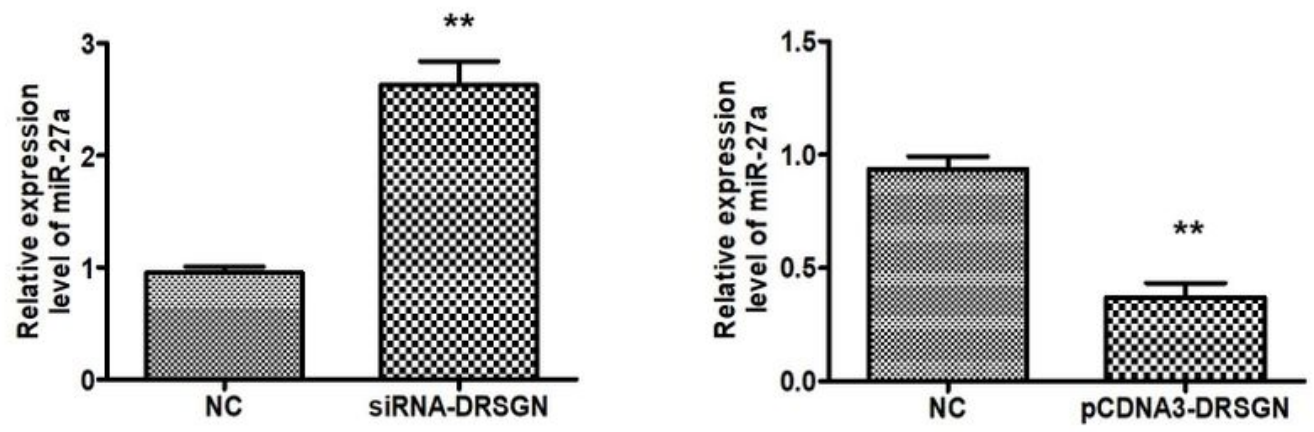

d

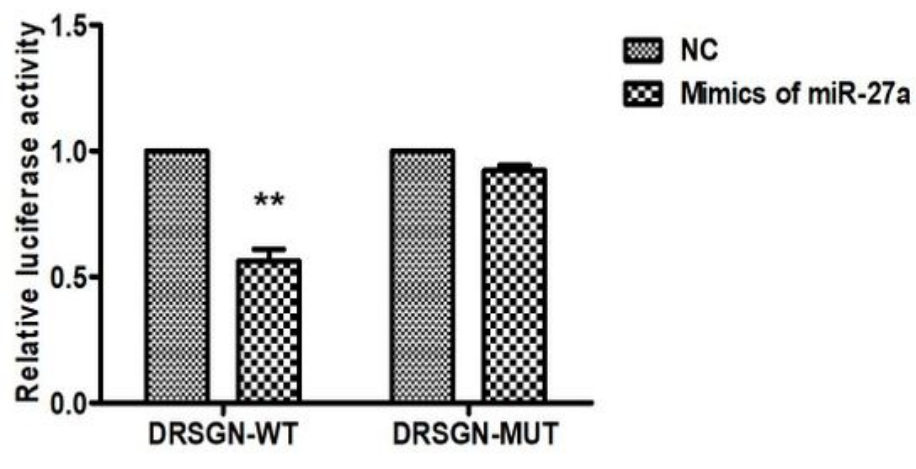

e

f

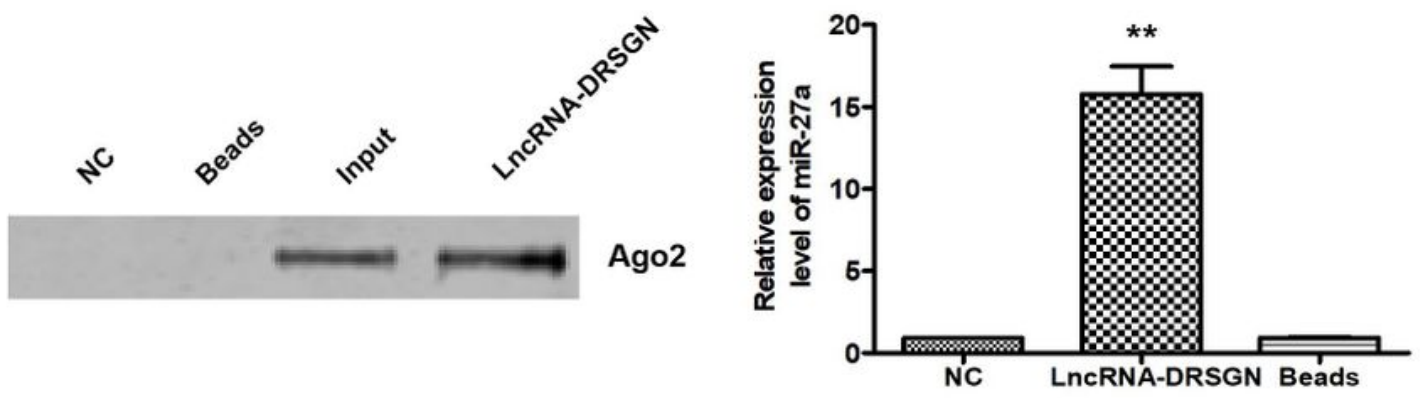

Figure 5

LncRNA-DRSGN could inhibit the expression of miR-27a as a ceRNA.

Two bioinformatics software DIANA-LncBase and miRcode were used to predict the combination between miRNAs and IncRNAs with differential expression selected from sequencing experiment. Then, the combination between miR-27a and LncRNA-DRSGN was forecasted (A). 
The over-expression (B) and knockdown (C) of LncRNA-DRSGN altered the expression level of miR-27a. Dual-luciferase reporter assay was used to confirm the combination between LncRNA-DRSGN and miR27a (D). Ago protein bands were detected in primary SGNs extraction incubated with LncRNA-DRSGN (E) and the higher miR-27a level was detected in LncRNA-DRSGN-pulled-down pellets (F). (Negative control, NC; $* * P<0.01)$

a

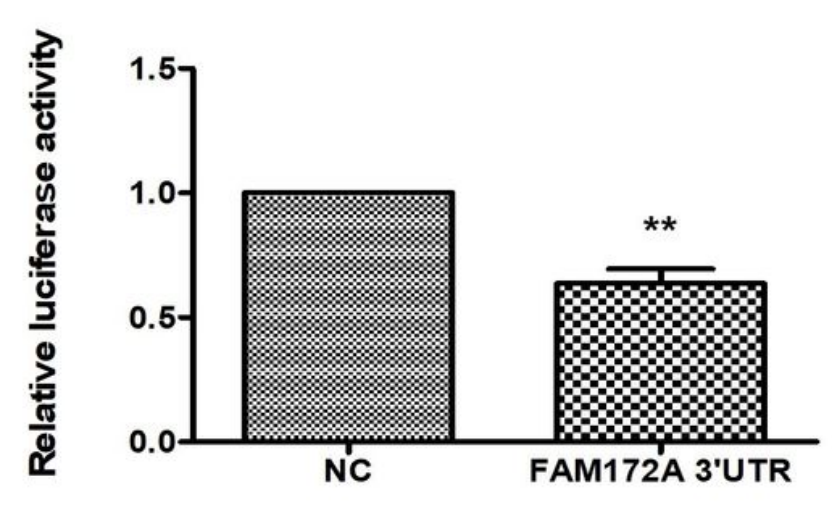

C

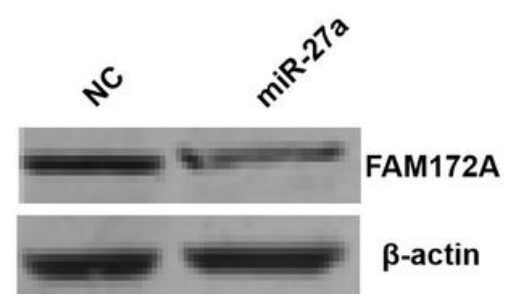

b

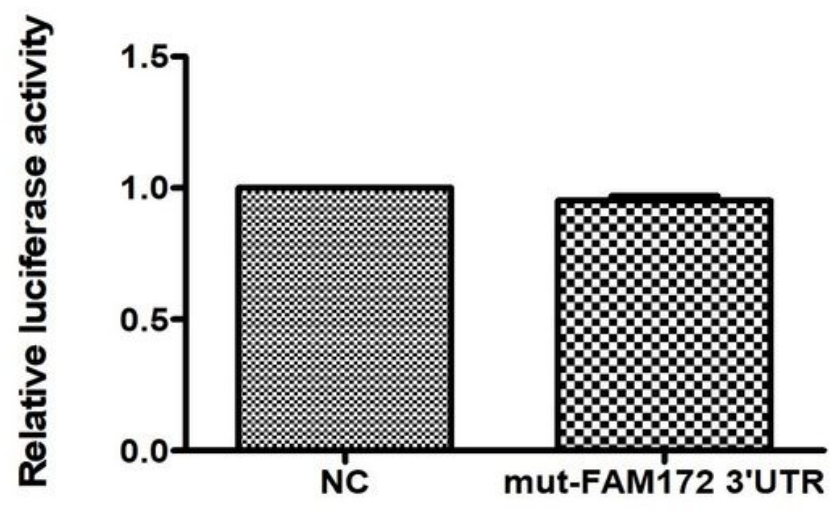

Figure 6

miR-27a inhibited FAM172A expression in Neuro 2A cells.

The 3' UTR luciferase activities of FAM172A significantly down-regulated in Neuro 2A cells dealt with mimics of miR-27a (A). However, it did not show obviously change in the group with FAM172A mutation (B). The results of western blot experiment demonstrated miR-27a suppressed FAM172A proteins expression in Neuro 2A cells (C). 
a

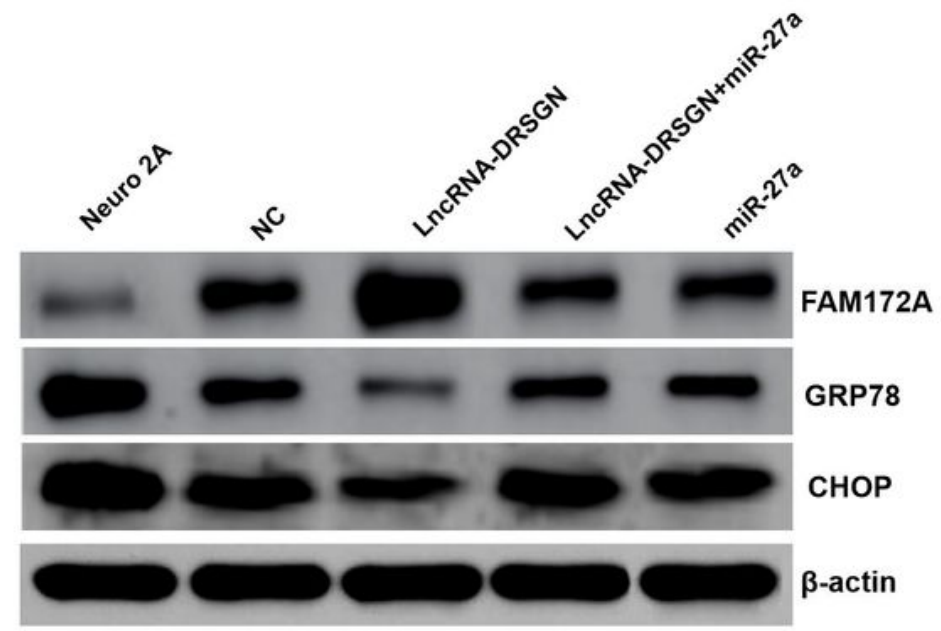

b

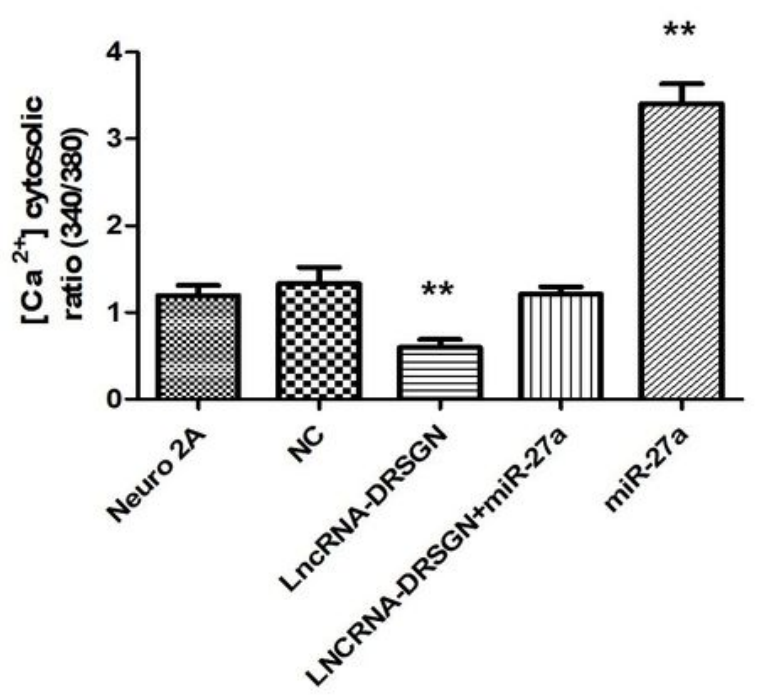

C
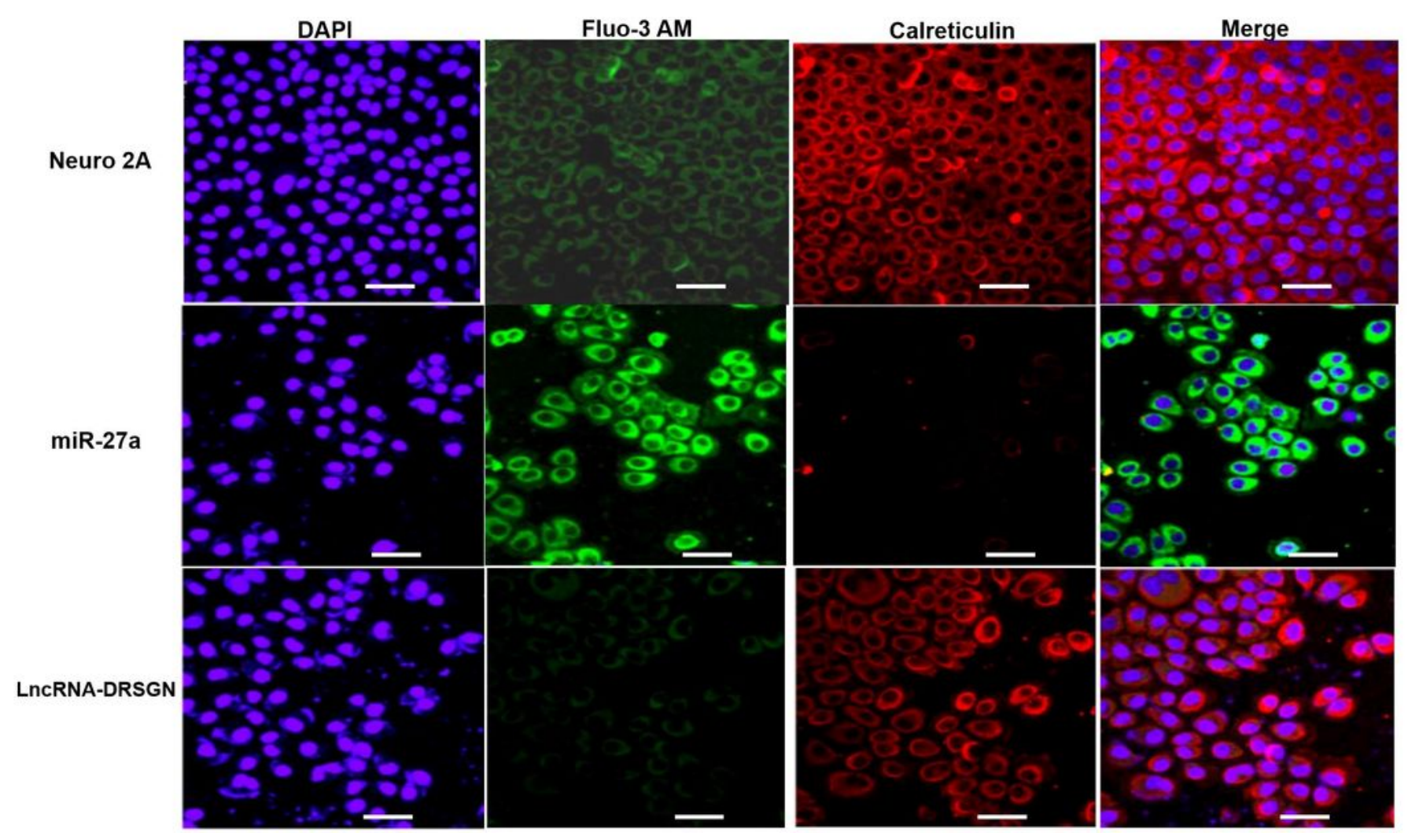

Figure 7

LncRNA-DRSGN competed with miR-27a for binding to FAM172A participated in the regulation of endoplasmic reticulum stress-related calcium flux.

LnCRNA-DRSGN resulted in increased expression levels of FAM172A, but the decreased expression levels of GRP78 and CHOP in the cell line. On the contrary, miR-27a caused a significant increase in the 
expression levels of GRP78 and CHOP in the cell line through suppressing the expression of FAM172A. But, the above bio-function induced by miR-27a could be reversed with LncRNA-DRSGN (A). Furthermore, LncRNA-DRSGN significantly inhibited intracellular calcium flux $(P<0.01)$. On the contrary, miR-27a resulted in a significant promotion of intracellular calcium flux $(P<0.01)$. But, the calcium flux caused with miR-27a could be reversed by LncRNA-DRSGN (B). LncRNA-DRSGN inhibited the protein expression of ERstress pathway resulted in a significant decrease of intracellular calcium flux $(P<0.01)$. On the contrary, miR-27a significantly promoted intracellular calcium flux $(P<0.01$; Scale bars is $5 \mu \mathrm{m})(\mathbf{C})$. 

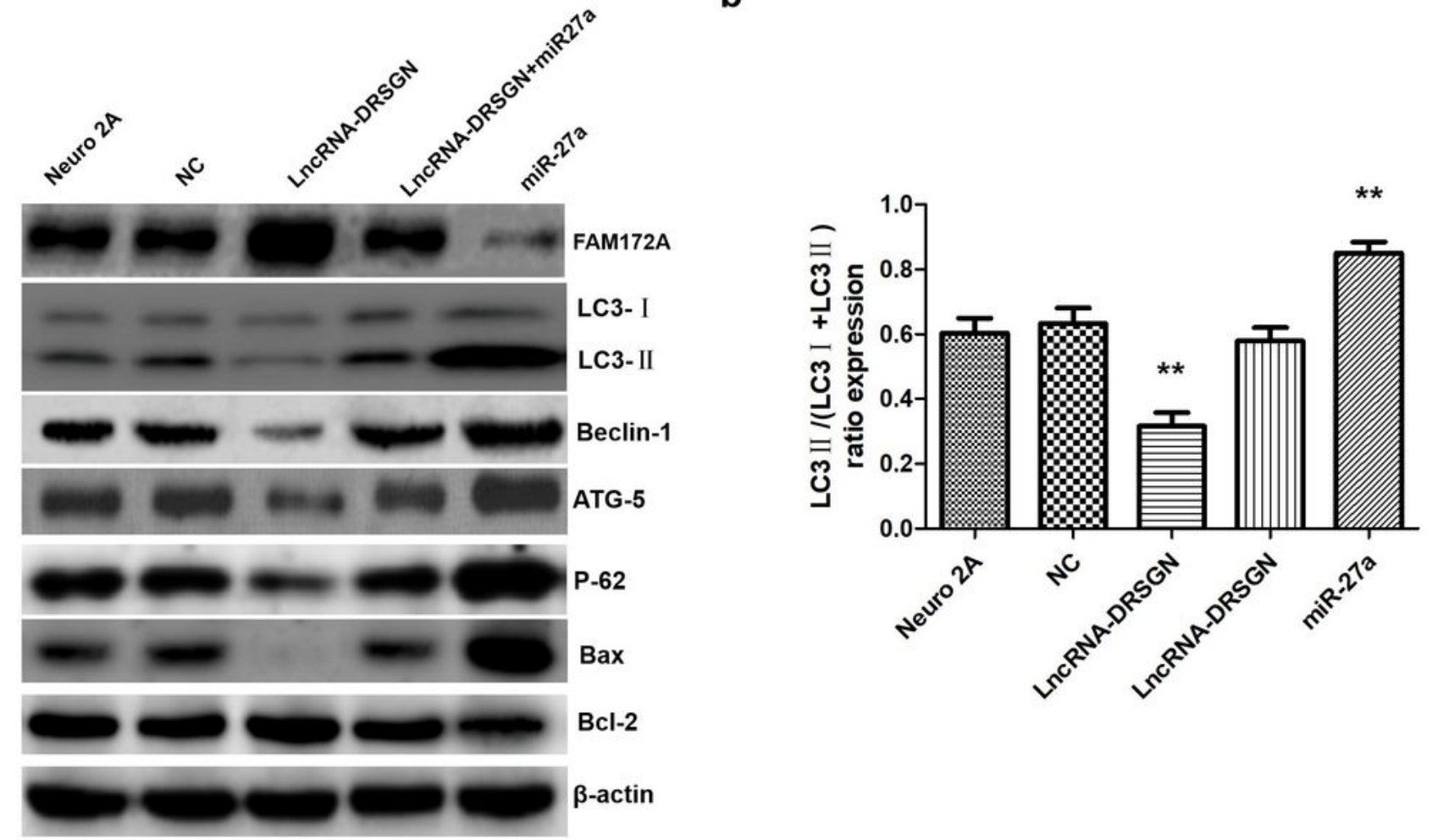

C

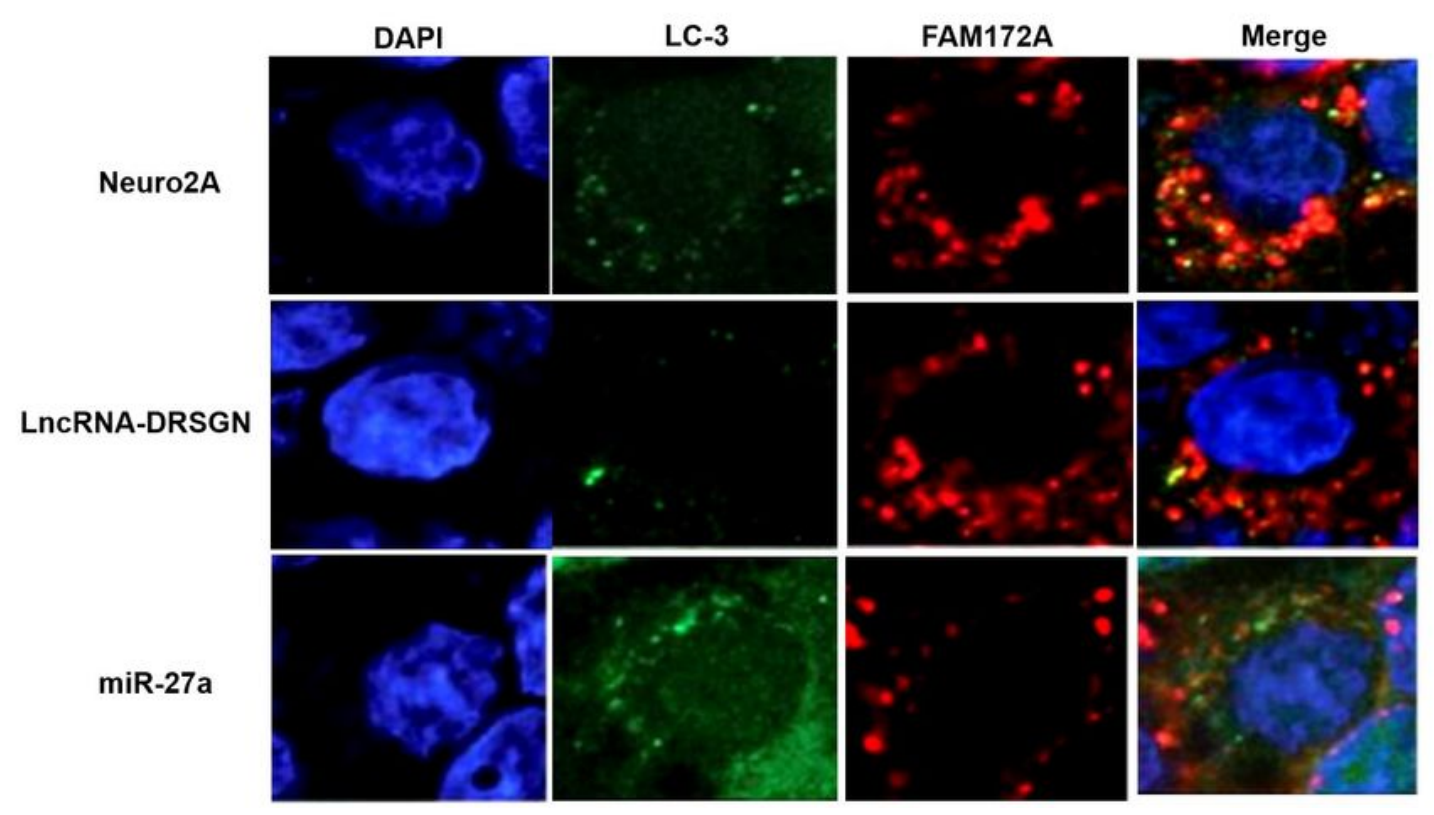

Figure 8

LncRNA-DRSGN competed with miR-27a for binding to FAM172A participated in regulating autophagy of Neuro 2A cells.

LncRNA-DRSGN resulted in a decreased expression ratio of the autophagy marker protein LC3- $\$ in Neuro 2A. On the contrary, with the interference of FAM172A expression with miR-27a mimics made for a visible 
increased expression ratio of the autophagy marker protein LC3-II in Neuro 2A cells (A and B). LncRNADRSGN prohibited miR-27a and induced over-expression of FAM172A resulted in decreased expression of Beclin-1, ATG-5 and p62. In addition, LncRNA-DRSGN inhibited the expression level of Bax, and promoted the expression of Bcl-2. But, miR-27a could induce all above reversed affection in Neuro 2A cells (A).

By inhibited miR-27a, LncRNA-DRSGN caused FAM172A over-expression, then restrained the autophagy process of Neuro 2A cells based on laser confocal microscopy. However, inhibiting the expression of FAM172A with miR-27a promoted the autophagy process of Neuro 2A cell line (C). 